\title{
Axillary nodal metastases from carcinoma of unknown primary (CUPAx): a systematic review of published evidence
}

\author{
George Pentheroudakis · George Lazaridis • \\ Nicholas Pavlidis
}

Received: 23 July 2009/Accepted: 10 September 2009/Published online: 22 September 2009

(C) Springer Science+Business Media, LLC. 2009

\begin{abstract}
Axillary lymph node metastases from adenocarcinoma or poorly differentiated carcinoma of unknown primary (CUPAx) represent a rare clinical entity without consensus on its biology, management and outcome. We systematically reviewed published CUPAx series and identified 24 retrospective studies enrolling 689 patients from 1975 till 2006. CUPAx affected women at a mean age of 52 years, $66 \%$ of whom post-menopausal harbouring low-volume $(\mathrm{N} 1,48 \%)$ or high-volume $(52 \%)$ nodal disease from ductal adenocarcinoma (83\%). Among a total of 446 patients managed with mastectomy, a small breast primary was identified histologically in 321 ( $72 \%$ of cases). Hormone receptor protein expression was observed in 40$50 \%$ of cases, while HER2 overexpression in $31 \%$. CUPAx patients were managed with axillary lymph node dissection coupled to mastectomy (59\%), primary breast irradiation $(26 \%)$ or observation $(15 \%)$. Observation was associated with high locoregional relapse rates (42\%) and risk of metastatic spread. Mastectomy or radiotherapy provided locoregional disease control in $75-85 \%$ of cases, while adjuvant systemic therapy was associated with a nonsignificant trend for improved survival in few series. Five-year survival ranged from 59.4 to $88 \%$ at a median follow-up of 62 months (mean 5-year survival 72\%), with axillary tumour burden being the pivotal prognostic factor. CUPAx is associated with similar presentation, biology and
\end{abstract}

Electronic supplementary material The online version of this article (doi:10.1007/s10549-009-0554-3) contains supplementary material, which is available to authorized users.

G. Pentheroudakis $(\bowtie) \cdot$ G. Lazaridis $\cdot$ N. Pavlidis

Department of Medical Oncology, Ioannina University Hospital, Niarxou Avenue, Ioannina 45500, Greece

e-mail: gpenther@otenet.gr outcome to resected node-positive overt breast cancer and should be treated accordingly.

Keywords Axillary metastases ·

Cancer of unknown primary $\cdot$ Prognosis

\section{Introduction}

The fundamental characteristics of cancer of unknown primary (CUP) are early dissemination and unpredictable metastatic pattern coupled to dormancy or regression of the primary tumour and aggressive biologic behaviour [1]. Among the most important advances in understanding CUP biology was the identification of favourable clinicopathologic subsets affecting 10-20\% of patients with CUP. Appropriate diagnosis of such cases is of great importance as they warrant specific treatment, which is frequently effective. Adenocarcinoma or poorly differentiated carcinoma found in isolated unilateral axillary lymph nodes without an obvious primary tumour (CUPAx) is a clinical situation challenging for physician and patient alike. The standardized diagnostic approach for investigation of the primary and staging consists of bilateral mammography, CT of chest/abdomen/pelvis supplemented by sign- or symptom-directed additional radiologic or endoscopic studies $[1,2]$. Malignant neoplasms known to metastasize to the axilla include lymphoma, melanoma and carcinomas of the breast, lung and gastrointestinal tract [3]. When the diagnosis is an adenocarcinoma or undifferentiated carcinoma, the most frequent culprit is breast cancer and a thorough investigation for a breast primary is warranted. Haematoxylin-eosin light microscopy examination supplemented by immunohistochemistry including oestrogen receptor (ER), progesterone receptor $(\mathrm{PgR})$ protein expression may 
contribute to precise identification of the cellular origin of the malignancy. Still, no consensus exists on a common battery of immunohistochemical studies, on the sequence of imaging modalities to be used, nor on the management strategy of these patients. Areas of dubiety include the management of the axilla, the need for surgical or radiotherapeutic extirpation of the presumed primary in the breast, the impact on patient outcome of adjuvant systemic chemotherapy or hormonal therapy. Moreover, prognosis of patients with CUPAx has not been clearly defined or related to the outcome of patients with node-positive breast cancer.

Due to its relative rarity there are no published randomized trials regarding management and outcome of patients with CUPAx, the only evidence for this entity originating from small retrospective studies. We sought to systematically review and analyse published data from prospective or retrospective studies of CUPAx patients in order to present available evidence on epidemiology, diagnosis, management and outcome as well as reach appropriate recommendations.

\section{Patients and methods}

We did a search of PubMed, MEDLINE and EMBASE using the following keywords for our literature search (cancer OR carcinom* OR neoplas* OR malignan* OR tumour OR tumour) AND (unknown primary OR unknown origin OR occult primary) AND (breast OR axilla* OR axillary lymph node metastases), restricting our search to English language. We also searched oral presentations at ESMO and ASCO conferences. Eligible patients were those with isolated axillary lymphadenopathy with adenocarcinomatous or carcinomatous deposits without evidence of primary tumour or distant metastatic deposits at initial diagnostic work-up. Histopathological identification of an occult breast tumour in subsequent mastectomy specimens or at autopsy did not exclude these patients from the CUPAx population. All patients had undergone bilateral mammographic imaging in order to be eligible for inclusion in the CUPAx cohort. All those in whom baseline imaging showed a breast lesion histologically confirmed as the primary tumour were not classified in the CUPAx population and were excluded from further analysis. A PRISMA flow diagram is presented in Supplementary figure [4].

\section{Results}

We identified 30 studies dealing with CUPAx patients, but we did not include in our analysis six of them because three had an update study and three had overlapping patients with series that were published over the following years from the same institutes [5-31]. Accordingly, a total of 689 patients presented with axillary carcinomatous metastases of unknown primary in 24 clinical series published from 1975 until 2006. All were small retrospective studies, making it difficult to draw solid conclusions based solely on low-level evidence. The last search update was performed in July 2009.

Demographics—patient and tumour characteristics

The true incidence of CUPAx seems to range from 0.12 to $0.67 \%$ of all diagnosed malignancies. Patient and tumour characteristics are summarized in Table 1 . Mean age at diagnosis was 52.4 years and in $66 \%$ of the cases it appeared in postmenopausal women. Following axillary clearance mean nodal size was $2.4 \mathrm{~cm}(0.5-10 \mathrm{~cm})$ with $52 \%$ of patients harbouring N2-3 disease (four or more involved nodes), according to pathologic TNM staging. A positive family history of malignancy could be identified in $23.4 \%$ of the CUPAx patients. In CUPAx patients managed with ipsilateral mastectomy in whom an occult primary tumour was identified on histopathologic

Table 1 Patient and tumour characteristics

\begin{tabular}{|c|c|}
\hline Number of studies & 24 \\
\hline Years (of publication) & 1975-2007 \\
\hline Incidence ( $\%$ of all malignancies) & $0.12-0.67 \%$ \\
\hline Total number of patients & 689 \\
\hline Gender & All females \\
\hline Mean age at diagnosis (range) & $52.4(32-79)$ \\
\hline Median follow-up of patients & 42 months (15 studies) \\
\hline \multirow[t]{3}{*}{ Laterality } & $\begin{array}{l}\text { Data from } 9 \text { studies } \\
(N=270)\end{array}$ \\
\hline & Left $146(54 \%)$ \\
\hline & Right $124(46 \%)$ \\
\hline \multirow[t]{4}{*}{ Menopausal status } & $\begin{array}{l}\text { Data from } 9 \text { studies } \\
\quad(N=203)\end{array}$ \\
\hline & Premenopausal $=64(31.5 \%)$ \\
\hline & Postmenopausal $=134(66 \%)$ \\
\hline & Perimenopausal $=5(2.5 \%)$ \\
\hline \multirow[t]{3}{*}{ Mean axillary size (range) } & Data from 7 studies \\
\hline & $2.4 \mathrm{~cm}$ \\
\hline & $(0.5-10 \mathrm{~cm})$ \\
\hline \multirow[t]{2}{*}{$\begin{array}{l}\text { Positive Family History for } \\
\text { malignancy }\end{array}$} & $\begin{array}{l}\text { Data from } 7 \text { studies } \\
(N=184)\end{array}$ \\
\hline & $43 / 184(23.4 \%)$ \\
\hline \multirow[t]{3}{*}{ Nodal status (pN) } & $\begin{array}{l}\text { Data from } 12 \text { studies } \\
\quad(N=384)\end{array}$ \\
\hline & $\mathrm{N} 1=184 / 384(48 \%)$ \\
\hline & $\mathrm{N} 2-3=200 / 384(52 \%)$ \\
\hline
\end{tabular}


Table 2 Occult breast primaries in mastectomy specimens

\begin{tabular}{|c|c|c|c|c|}
\hline & $\begin{array}{l}\text { All CUPAx } \\
\text { patients }\end{array}$ & $\begin{array}{l}\text { Invasive tumours } \\
\text { found in breast }\end{array}$ & $\begin{array}{l}\text { In situ carcinomas } \\
\text { found in breast }\end{array}$ & $\begin{array}{l}\text { Number and size } \\
\text { of invasive tumours }\end{array}$ \\
\hline Owens [5] & 27 & 25 & & $\begin{array}{l}15<1 \mathrm{~cm} \\
5>1 \mathrm{~cm}\end{array}$ \\
\hline Feurman [6] & 2 & 1 & & \\
\hline Fitts [7] & 11 & 7 & & \\
\hline Haagensen [8] & 13 & 12 & & \\
\hline Ashikari [9] & 34 & 20 & 3 & $\begin{array}{l}7<1 \mathrm{~cm} \\
71-2 \mathrm{~cm} \\
6>2 \mathrm{~cm}\end{array}$ \\
\hline Feigenberg [10] & 4 & 3 & & \\
\hline Vezzoni [11] & 44 & 33 & & $\begin{array}{l}11<0.5 \mathrm{~cm} \\
120.5-1 \mathrm{~cm} \\
101-2 \mathrm{~cm}\end{array}$ \\
\hline Iglehart [31] & 5 & 5 & & $\begin{array}{l}3<1 \mathrm{~cm} \\
21-1.5 \mathrm{~cm}\end{array}$ \\
\hline Kemmeny [12] & 11 & 3 & 2 & $\begin{array}{l}2<2 \mathrm{~cm} \\
1>2 \mathrm{~cm}\end{array}$ \\
\hline Bhatia [13] & 11 & 9 & 2 & $\begin{array}{l}8<2 \mathrm{~cm} \\
1>2 \mathrm{~cm}\end{array}$ \\
\hline Rosen [16] & 38 & 27 & 7 & $\begin{array}{l}\text { Median } 1.5 \mathrm{~cm} \\
(0.1-6.5) \\
18<2 \mathrm{~cm} \\
4>2 \mathrm{~cm}\end{array}$ \\
\hline Ellerbroek [17] & 13 & 1 & & \\
\hline Merson [18] & 33 & 27 & & $\begin{array}{l}9<1 \mathrm{~cm} \\
61-2 \mathrm{~cm} \\
5>2 \mathrm{~cm}\end{array}$ \\
\hline Svastics [19] & 29 & 11 & & \\
\hline Van Ooijen [20] & 1 & 0 & & \\
\hline Kyokane [21] & 92 & 72 & 9 & $\begin{array}{l}\text { Median } \\
1 \mathrm{~cm}(1-10)\end{array}$ \\
\hline Vlastos [24] & 13 & 1 & & $2 \mathrm{~cm}$ \\
\hline Medina-Franco [25] & 3 & 0 & & \\
\hline Matsuoka [27] & 10 & 5 & 2 & $7<2 \mathrm{~cm}$ \\
\hline Blanchard [28] & 18 & 5 & 1 & $\begin{array}{l}\text { Mean } 2.9 \mathrm{~cm} \\
(1.5-6)\end{array}$ \\
\hline Chen [29] & 16 & 16 & & $\begin{array}{l}\text { Median } 1 \mathrm{~cm} \\
(0.5-1.5)\end{array}$ \\
\hline Total & 446 & $321(72 \%)$ & $26(5.8 \%)$ & \\
\hline
\end{tabular}

examination, the size of the primary lesion was less than $2 \mathrm{~cm}$ in $87 \%$ of cases $(43.5 \% 0-1 \mathrm{~cm}, 43.5 \% 1-2 \mathrm{~cm})$ (Table 2). Among a total of 446 patients managed with mastectomy, an occult breast primary was identified histologically in $321(72 \%)$. Though the impact of removing an occult primary on survival is not clear, these data support mastectomy as an effective diagnostic modality. Ductal or lobular carcinomas in situ were detected in 5$10 \%$ of mastectomy CUPAx cases, in keeping with published incidence in the general population.
Imaging of the breast

Data from 20 studies evaluating a total of 498 patients established a rate of radiologic identification of a primary lesion in $100(20 \%)$. The impact of application of highresolution digital mammography is currently unknown in this setting. Breast ultrasound performed in six studies of 84 CUPAx patients identified abnormalities in only $4 \%$ of cases and seems only to have a role for differentiation of cystic/solid lesions. Magnetic resonance imaging (MRI) of 
the breast managed to reveal a primary in 96 out of 162 patients (59\%), suggesting that it is a selected modality with high sensitivity for detection of occult breast tumours that may find a place in the diagnostic algorithm of CUPAx patients.

\section{Histology}

Histopathologic data were reported for the carcinomatous deposits in either axillary lymph nodes or the occult mammary tumour in 385 cases. The carcinomatous deposit in 319 ( $83 \%$ of cases) was a ductal carcinoma, lobular in 50 $(13 \%)$ and other types in $4 \%$. Good to moderate differentiation was observed in 342 (89\% of cases) while $43(11 \%)$ were poorly differentiated. Among 184 CUPAx tumours with available data, positive staining for oestrogen receptor was seen in 76/175 (43\%) and for progesterone receptor in $16 / 39$ (41\%). Only scarce data were available for immunohistochemical (IHC) HER2/neu protein overexpression (IHC $3+$ ), though the $31 \%$ incidence observed ( $4 / 13$ cases) is in the range reported for node-positive breast cancer.

\section{Axillary management}

A level I and II axillary lymph node dissection (ALND) was routinely practiced by the vast majority of investigators in the published series (92\% of CUPAx patients). In the minority of cases, in which axillary excisional biopsy was applied, irradiation of the axilla followed. It is unknown if resection of involved lymph nodes only is suboptimal, though this is likely to result in residual disease left in lymph nodes microscopically involved. In 1976 Feigenberg et al. [10] reported a 50\% recurrence rate when the axilla is treated only with RT and recommended ALND as an essential component of the primary treatment of patients with CUPAx in view of the benefits in local control of the disease. In-axilla failure rates were generally lower after a level I/II ALND at less than 10\% and higher (20-50\%) when excisional biopsy and/or axillary irradiation were used. These data argue in favour of ALND as the preferred treatment that offers diagnostic and therapeutic benefit. Management and outcome data on analysed clinical series are shown in Tables 3, 4, 5 and 6.

Management of the ipsilateral breast

Treatment of the ipsilateral breast in patients with CUPAx remains controversial. Treatment options that have been tested in the above mentioned studies include: mastectomy, breast conserving surgical excision of suspicious lesions and whole breast radiotherapy, external beam breast irradiation only and observation. In 59\% primary treatment consisted of mastectomy with or without chest wall
Table 3 Clinical series with breast observation only

\begin{tabular}{llll}
\hline & $N$ & Breast failure & Latent period (months) \\
\hline Haagensen [8] & 5 & $3 / 5$ & Range 5-64 \\
Feigenberg [10] & 4 & $0 / 4$ & \\
Kemmeny [12] & 7 & $0 / 7$ & \\
Bhatia [13] & 2 & $2 / 2$ & Median 6.2 \\
Campana [14] & 1 & $1 / 1$ & Median 7 \\
Rosen [16] & 5 & $0 / 5$ & \\
Ellerbroek [17] & 13 & $7 / 13$ & Median 27 \\
& & & Range 11-47 \\
Merson [18] & 17 & $9 / 17$ & Mean 13 \\
Svastics [19] & 14 & $2 / 14$ & Median 4,1 \\
Van Ooijen [20] & 14 & $2 / 14$ & Median 10.3 \\
Jackson [22] & 8 & $7 / 8$ & Mean 15 months \\
& & & Range 6-39 \\
Foroudi [23] & 6 & $5 / 6$ & Median 7 \\
Shannon [26] & 13 & $7 / 13$ & \\
Matsuoka [27] & 1 & $1 / 1$ & Median 37 \\
Total & & $46 / 110(42 \%)$ & \\
\hline
\end{tabular}

$N$ sample size

Table 4 Therapy of CUPAx patients

\begin{tabular}{ll}
\hline Treatment data available for $N=600$ patients & $N(\%)$ \\
\hline Primary therapy & \\
Axillary lymph node dissection only & $61(10)$ \\
Axillary excisional biopsy only & $31(5)$ \\
Mastectomy (with axillary local treatment) & $240(40)$ \\
Mastectomy + chest wall RT & $111(19)$ \\
$\quad$ (with axillary local treatment) & $157(26)$ \\
Primary breast RT (with axillary local treatment) & \\
Adjuvant systemic therapy & $239(40)$ \\
Chemotherapy (with or without endocrine) & $71(12)$ \\
Hormonotherapy (with or without chemotherapy) & $57(10)$ \\
Combined chemohormonotherapy & $132 / 600(21)$ \\
Anthracycline-based & $5 / 600(1)$ \\
Anthracycline + taxane combinations & $102 / 600(18)$ \\
Alkylator-based &
\end{tabular}

$R T$ radiation therapy, $N$ sample size

radiotherapy. Whole breast irradiation was the primary treatment in $26 \%$, while observation of the breast was chosen in $15 \%$ of cases (Table 4 ).

A standard approach in several series was to perform a "blind" modified radical mastectomy at the time of ALND. In our review we observed that a breast malignancy was found upon histologic review of the breast specimen in $72 \%$ of the resected cases with an additional $5.8 \%$ of DCIS (Table 2). Radical whole-breast radiotherapy has been used as an alternative to mastectomy, though there are no 
Table 5 Outcome and prognosis

\begin{tabular}{|c|c|c|c|}
\hline Mean 5-year overall survival & \multicolumn{3}{|c|}{$\begin{array}{l}\text { Available data from } 14 \text { studies } \\
N=559 \\
\text { OS }=72 \% \\
\text { (Range } 59.4-87.5 \% \text { ) } \\
\text { Median follow-up } 62 \text { months (range } 27-133 \text { ) }\end{array}$} \\
\hline Prognostic/predictive factors $(P<0.05)$ & \multicolumn{3}{|l|}{ Investigators } \\
\hline Number of involved axillary lymph nodes & \multicolumn{3}{|c|}{ Kemmeny [12], Svastics [19], Whillis [15], Merson [18], Kyokane [21], Vlastos [24] } \\
\hline ALND & \multicolumn{3}{|l|}{ Ellerbroek [17] } \\
\hline Absence of residual gross disease & \multicolumn{3}{|l|}{ Ellerbroek [17] } \\
\hline Local treatment of breast (surgery or RT) & \multicolumn{3}{|c|}{ Vlastos [24], Foroudi [23], Shannon [26], Blanchard [28] } \\
\hline \multirow[t]{2}{*}{ Impact of adjuvant systemic therapy } & \multicolumn{3}{|l|}{ 5-year overall survival } \\
\hline & Adjuvant therapy $(\%)$ & No adjuvant therapy (\%) & 2-sided $P$ \\
\hline Ellerbroek $(n=42)[17]$ & 92 & 67 & 0.15 \\
\hline Shannon $(n=29)[26]$ & 88 & 86 & 0.4 \\
\hline Merson $(n=56)[18]$ & 87 & 79 & 0.2 \\
\hline \multirow{2}{*}{$\begin{array}{l}\text { Blanchard }(n=35)[28] \\
\text { (mastectomised patients } n=18 \text { ) }\end{array}$} & 55 & 65 & 0.59 \\
\hline & 97 (3-year OS) & 75 (3-year OS) & \\
\hline
\end{tabular}

$N$ sample size, $O S$ overall survival, $A L N D$ axillary lymph node dissection, $R T$ radiation therapy

randomized trials directly comparing these two approaches. Published breast only control rate ranged from 75 to $100 \%$ (Table 6). The natural history of CUPAx when the ipsilateral breast is not treated is provided in Table 3. A breast primary subsequently developed in the untreated breast in $42 \%$ of cases (46/110 in our review) with a latent period from the initial diagnosis of 4-64 months.

\section{Observation versus local treatment}

Despite the high incidence of occult primary identification in breast pathology specimens, certain series came to question the need for a mastectomy. Though some small series suggested absence of a survival difference whether the breast was treated or not, their small sample size precluded identification of small or moderate differences in outcome. In fact, series with larger sample sizes identified superior survival of CUPAx patients who had the ipsilateral breast treated with mastectomy or irradiation at diagnosis rather than observed. Statistical significance of these survival differences was reached occasionally.

In 1990 Ellerbroek et al. [17] presented a series of 42 patients of whom 13 were treated with mastectomy, 16 with breast irradiation and 13 observed. They reported that breast cancer-free 5-year survival was $83 \%$ for patients who had their breasts conserved but treated with irradiation versus $43 \%$ for those who were managed with observation $(P=0.06)$. In 1991 Merson et al. [18] reported 5-year survival rates of $80 \%$ for 39 CUPAx patients managed with breast resection or irradiation versus $65 \%$ for 17 patients observed until disease relapse, a difference not statistically significant. In two other series by Rosen et al. and Jackson et al. [16, 22], among 17 patients who opted for breast observation 13 experienced disease relapse or death, prompting the authors to suggest that observation is not an acceptable treatment option for CUPAx patients. In 2000 Foroudi et al. [23] further confirmed these data as they reported local recurrence rates of $100 \%$ for the observation group versus $30 \%$ for the group receiving breast irradiation and $0 \%$ for the mastectomy group. Patients in the observation group had poorer RFS when compared to the groups on local treatment (median RFS 7 versus 182 months, $P=0.003$ ). Finally, in 2004 Blanchard et al. reported 5year RFS and OS of 64 and $73 \%$ in resected patients versus only 19 and $36 \%$, respectively in patients who retained their breasts $(P<0.05)$. Overall, these data show the inferiority of breast observation versus mastectomy in terms of disease control and survival.

\section{Whole breast irradiation}

The use of whole breast irradiation was first reported by Vilcoq in 1982 [32] and was reinforced by subsequent data. In 1989 Campana et al. [14] reported 5- and 10-year survival rates of 76 and $71 \%$ in 31 CUPAx patients managed with conservative breast radiotherapy (RT), while Whillis et al. [15] similarly published a 5-year actuarial survival of $66 \%$ in 18 patients treated with breast radiotherapy. In 


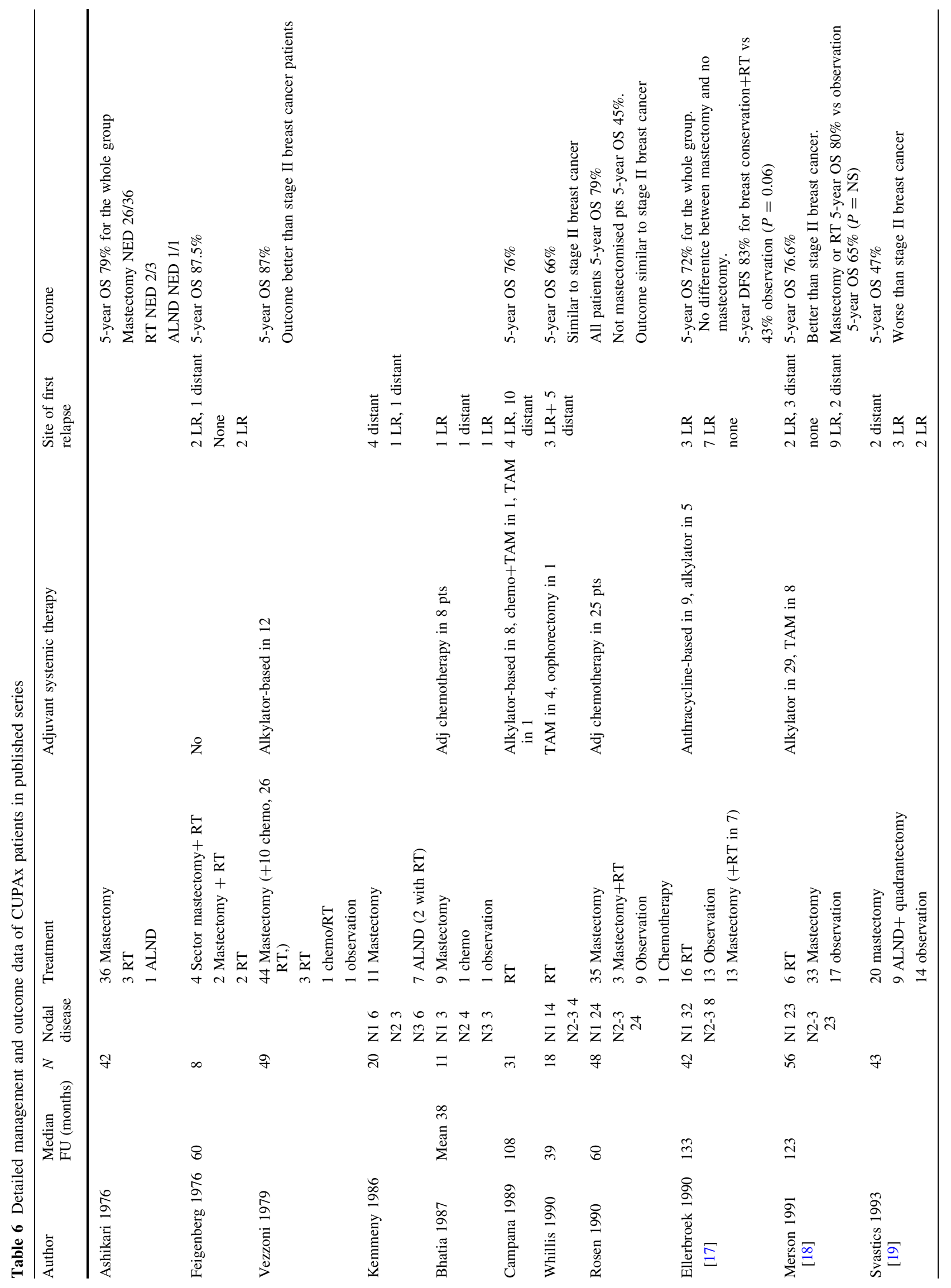




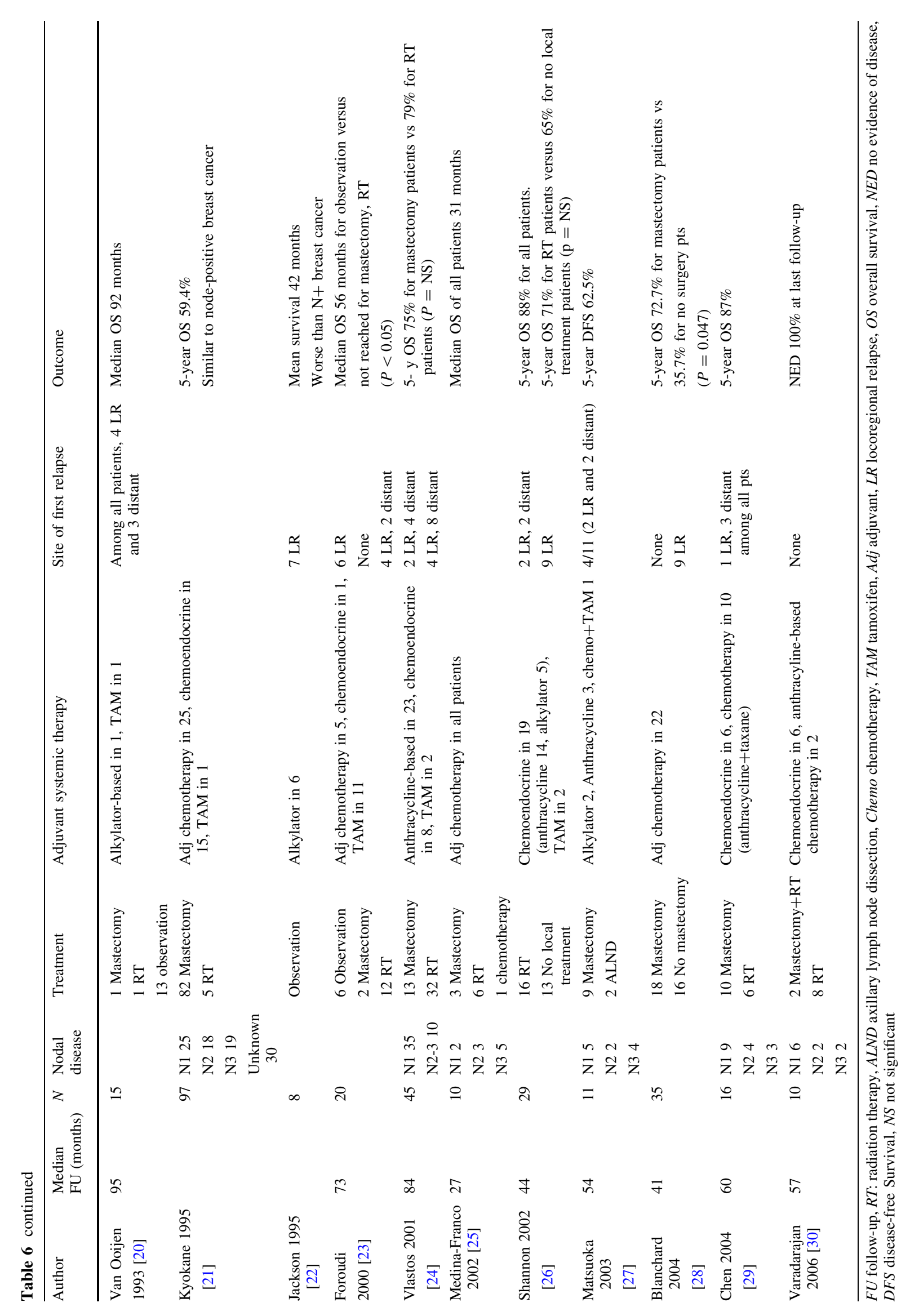


2002 Shannon et al. [26] published data on 16 CUPAx patients treated with breast RT and 13 who were observed. Convincingly, patients who received radiotherapy had better relapse-free survival ( $\mathrm{HR}=0.31, P=0.04)$, though there was no significant difference in overall survival (HR $=1.04 ; 95 \%$ CI 0.2-5). In 2001, Vlastos et al. [24] presented a retrospective series of 45 patients with CUPAx and reported no significant difference between mastectomy versus breast conserving surgery and irradiation in terms of locoregional recurrence ( $15 \%$ versus $13 \%, P=0.9)$, distant metastases (31\% versus $22 \%, P=0.53$ ) and 10 -year survival $(66 \%$ versus $64 \%, P=0.9$ ). This study was further supported by similar efficacy of mastectomy versus breast irradiation reported by Medina-Franco et al. [25]. In contrast to data presented by Foroudi et al., cumulative experience from all those series suggested that in the absence of gross breast abnormalities, breast irradiation coupled to surgical extirpation of axillary disease, is feasible and effective in achieving favourable local control rates and survival.

\section{Adjuvant systemic therapy}

Adjuvant systemic therapy was commonly administered according to clinical guidelines used for patients with resected node-positive breast cancer. This was more often the case for clinical series published after 1990, when the utility of adjuvant therapy had been firmly established in early breast cancer. Among 600 patients with available data, chemotherapy was administered in 239 (40\%), with or without endocrine therapy. Seventyone patients $(12 \%)$ received endocrine therapy, almost exclusively tamoxifen, alone or combined with chemotherapy. Fifty-seven patients (10\%) were managed with combined chemoendocrine therapy. Administered adjuvant chemotherapy consisted of anthracycline-based regimens in 132/600 (21\%), anthracycline-taxane combinations in five $(1 \%)$ and alkylating regimes (CMF variants) in 102/600 (18\%).

As most series were retrospective and small, the impact of systemic adjuvant therapy on patient outcome could not be assessed. However, in four studies data on outcome of patients managed with and without adjuvant therapy were provided. Outcome seems to be superior for patients managed with adjuvant chemotherapy in the series published by Ellerbroek et al. (5-year OS 92\% versus $67 \%$, $P=0.15$ ) [17] and Merson et al. (5-year OS $87 \%$ versus $79 \%, P=0.2$ ) [18], while no difference is seen in the Shannon series (5-year OS $88 \%$ versus $86 \%, P=0.4$ ) [26]. Finally, in the series by Blanchard et al. [28], survival may be positively influenced by adjuvant chemotherapy only in patients managed with mastectomy (3-year OS $97 \%$ versus $75 \%, P>0.05)$, the ones most likely not harbouring gross tumour burden. Data on adjuvant chemotherapy are summarized in Tables 4 and 5.

Outcome and prognosis

5 -year survival in the series analysed ranged from 59.4 to $88 \%$ at a median follow-up of 62 months (Table 5). Five year survival data were quoted in 14 studies for a total of 559 CUPAx patients, the mean 5-year OS rate being $72 \%$. When compared to the survival of node-positive (pN1-3, stage II-III) breast cancer patients, CUPax seemed to have a favourable or similar prognosis. In particular, three series $[11,16,28]$ reported favourable outcome of CUPAx patients in comparison to patients with resected nodepositive overt breast cancer, while two found similar outcomes for these two patient cohorts $[15,21]$. These comparisons were only matched for stage and involved historical controls, thereby constituting a low level of evidence. On the contrary, Svastics et al. [19] and Jackson et al. [22] argued that patients with CUPAx fared worse that matched patients with stage II breast cancer. Regarding clinicopathologic prognosticators nodal burden was recognized as the sole factor of prognostic significance $[12,15$, $18,19,21,24]$, with patients with N1 disease (1-3 involved axillary lymph nodes) experiencing better locoregional disease control, fewer distant failures as well as superior overall survival when compared to patients with N2-3 disease. Other parameters with reported favourable prognostic or predictive significance were performance of axillary nodal dissection and absence of gross disease after surgery [17], local treatment of the ipsilateral breast by means of mastectomy or irradiation [23, 24, 26, 28]. Data on outcome of patients with CUPAx are shown in Tables 5 and 6 .

\section{Discussion}

Women with adenocarcinoma or carcinoma involving only axillary lymph nodes represent such a relatively rare CUP cohort of patients who may enjoy long-term survival [33]. In our review, we analysed clinicopathologic, management and outcome data on 689 patients with CUPAx in order to shed light in one pivotal query: is this entity a variant of node-positive breast cancer or are there significant biologic differences between the two? A second objective was to distill even low-level evidence from published CUPAx series in order to formulate recommendations that may contribute to standardisation of the management of these patients.

Although a non-palpable lesion is identified mammographically in 10-20\% of breast cancer cases, many occult non-palpable tumours are missed because of their small size (up to $30 \%$ of occult tumours being $<5 \mathrm{~mm}$ ) or are 
obscured by dense fibroglandular tissue [4, 34]. A negative mammogram should prompt imaging of the breast with ultrasound and/or breast magnetic resonance imaging (MRI), which is more sensitive than either mammography or breast ultrasound [35]. In our review of CUPAx patients, breast MRI identified a primary in $59 \%$ of 162 cases, data that confirm accuracy rates published previously $[35,36]$. The identification of a primary breast cancer by MRI may facilitate breast conserving surgery instead of mastectomy. However, breast MRI is also characterized by high falsepositive rates ( $29 \%$ in one study), therefore biopsy of suspicious lesions is advisable [37].

Basic clinicopathologic data of CUPAx patients are not dissimilar to those of patients affected by overt stage II or III breast cancer. It is known that axillary nodal metastases may stem from primaries $<1 \mathrm{~cm}$ : in fact, in a report of 953 breast cancer patients, axillary metastases were detected in $20 \%$ of those with tumours smaller than $1 \mathrm{~cm}$ [38, 39]. In our CUPAx review, a definition bias may be responsible for the high percentage of well differentiated tumours, as in several series adequate tissue differentiation towards glandular morphology was a prerequisite for inclusion in the CUPAx cohort. The incidence of CUPAx hormone-receptor positivity (40-50\%) or HER2 overexpression (30\%) is in agreement with accumulated experience from overt breast cancer [40]. In surgical series, blind mastectomy resulted in histologic detection of a small primary in $72 \%$ of cases, a finding further supporting the absence of biologic differences between CUPAx and early breast cancer. However, it is striking that despite a $72 \%$ rate of histologic identification of an occult breast tumour in mastectomy specimens, $60 \%$ among those managed with breast observation remained free from locoregional progression at follow-up times of 1-2 years. This finding suggests that the occult breast primary indeed grows more indolently than overt breast primaries.

Regarding management, ALND seems to be a necessary component of treatment because it offers superior staging, prognostic information as well as local control of disease, while associated with fewer side-effects (lymphedema) [41]. On the other hand, observation of the untreated axilla or breast is contra-indicated for several reasons: the rate of locoregional relapse in observed patients was $42 \%$ in our review and may be underestimated since several series had a short follow-up time of only 2-3 years, thus missing late relapses. Even considering the alternative of delayed treatment of the breast upon progression, the latter strategy provides plenty of time for expansion/divergence of the malignant clone, accumulation of further genetic damage and dissemination to distant sites [42]. Although all studies were retrospective and underpowered to show a statistically significant survival advantage for immediate versus delayed locoregional therapy, such a trend was present in six series published [16-18, 22, 23, 28].

Breast irradiation may be an alternative to mastectomy, resulting in locoregional recurrence rates of 15-25\%. Still, mastectomy is the only modality that provides unequivocal surgical extirpation of disease, data on presence of an occult primary, additional malignant tissue for testing, locoregional relapse rates of 5-15\% and obviates the need for radiologic follow-up of the conserved breast. Moreover, it is well known from breast cancer that irradiation does not make up for inadequate surgical excision of the primary with involved resection margins [43]. Therefore, despite the low level of evidence, we suggest that fit patients accepting mutilating surgery should undergo mastectomy of the ipsilateral breast.

Adjuvant chemotherapy was given in only $40 \%$ and hormonal therapy in $12 \%$ of CUPAx patients, probably due to inclusion of seven papers published in the seventies/ eighties, co-morbidity of some patients, failure to report related data and inherent belief of distinct biology. However, in view of lack of evidence for any biologic or outcome differences, CUPAx patients should receive adjuvant systemic therapy according to the indications for nodepositive early breast cancer (similarly, trastuzumab for HER2-overexpressing tumours) [44]. It should be reminded that seven of 10 CUPAx patients would be found to harbour a small breast primary on mastectomy. Moreover, in three series a trend for survival advantage in CUPAx patients receiving adjuvant therapy was suspected $[17,18$, 28] despite frequent lack of adequate management of the breast/axilla fully eradicating gross disease. No series provide information on use of neoadjuvant chemotherapy in patients with CUPAx: most patients undergo axillary nodal clearance immediately after fine needle aspiration/ excisional biopsy or in the presence of unresectable lymph nodes, axillary irradiation. However, in the case of fixed axillary nodal masses administration of neoadjuvant chemotherapy followed by nodal clearance in case of response could be a valid option.

The outcome of CUPAx patients compares favourably to that of patients with stage II or III overt breast cancer, as 5-year survival in CUPax series ranged from 59.4 to $88 \%$ [45]. Most clinical series reported that survival of CUPAx patients is not inferior to stage-matched patients with nodepositive resected breast cancer [11, 16, 18, 21, 28], with only two showing inferior prognosis (Jackson et al.; Svastics at al) [19, 22]. However, in the latter series a significant proportion of patients were managed with observation or blind quadrantectomy. Failure to treat the ipsilateral breast harbouring the occult primary probably resulted in the reported poorer outcome than patients with stage II breast cancer. The similar prognosis further establishes the biological similarity of CUPAx with overt 
early breast cancer, the two entities sharing the same pivotal prognosticator, axillary nodal status [46].

Overall, no molecular aberrations responsible for regression of the primary, early and atypical metastatic dissemination have been consistently identified in patients with CUP [33]. This observation reinforces what clinicians are already aware of, the heterogeneity of the group of tumours making up the CUP cohort. Deficits in angiogenesis of the primary tumour, early emergence of cellular clones with migratory phenotype, differential profile of the microenvironment/stroma in the primary organ and metastatic sites have been incriminated, but not proven to be the culprit. CUPAx seems to behave similarly to node-positive breast cancer, although in cases where no tumour is found in mastectomy, presence of subtle molecular differences responsible for regression of the primary should be hypothesized and sought for.

\section{Conclusions-recommendations}

- The epidemiology, biology and outcome of CUPAx patients are similar to that of patients with resected node-positive overt breast cancer.

- This is in contrast to cases of CUP with several visceral metastases which are biologically classified by microarrays as "breast cancer". Accordingly, there may exists two different clinical entities: (a) CUPAx which is the biologic equivalent of node-positive breast cancer, (b) poor risk visceral CUP "breast-like" which retains a molecular signature similar to breast cancer but harbours additional genetic aberrations.

- Bilateral mammography is needed, supplemented by bilateral breast MRI in negative cases, with biopsy of suspicious findings.

- ER, PR, HER2 status should be assessed in malignant tissue for diagnostic, prognostic and therapeutic purposes.

- Axillary lymph node dissection should be carried out as it offers optimal staging, prognostic information and local control. Breast/axilla observation is contraindicated.

- Mastectomy is preferable in a fit patient accepting mutilating surgery, as it provides breast screening for the primary, surgical extirpation of disease and obviates the need for follow-up of the breast. Breast irradiation is an alternative with acceptable locoregional failure of $15-25 \%$.

- Adjuvant systemic therapy (chemotherapy, hormonotherapy, trastuzumab) should be administered in fit patients without medical comorbidities, according to indications for node-positive breast cancer.

- Prognosis is similar to stage II-III overt breast cancer.
Conflict of interest statement The authors declare that they have no actual or potential conflict of interest including any financial, personal or other relationships with other people or organizations within that could inappropriately influence (bias) their work.

\section{References}

1. Pavlidis N, Briasoulis E, Hainsworth J, Greco FA (2003) Diagnostic and therapeutic management of cancer of unknown primary. Eur J Cancer 39:1990-2005

2. Pierce EH, Gray HK, Dockerty MB (1973) Surgical significance of isolated axillary adenopathy. Surgery 145:104-107

3. Copeland EM, McBride CM (1973) Axillary metastases from unknown primary sites. Ann Surg 178:25-28

4. Moher D, Liberati A, Tetzlaff J, Altman DG, The PRISMA Group (2009) Preferred Reporting Items for Systematic Reviews and Meta-Analyses: The PRISMA Statement. PLoS Med 6(6):e1000097. doi:10.1371/journal.pmed1000097

5. Owen HW, Dockerty MB, Gray HK (1954) Occult carcinoma of breast. Surg Gynecol Obstet 98:302-304

6. Feuerman L, Attie JN, Rosenberg B (1962) Carcinoma in axillary lymph nodes as an indicator of breast cancer. Surg Gynecol Obstet 114:5-8

7. Fitts WT, Steiner GC, Enterline HT (1963) Prognosis in occult carcinoma of the breast. Am J Surg 106:460-463

8. Haagensen CD (1971) The diagnosis of breast carcinoma. In: Haagensen CD (ed) Diseases of the breast. WB Saunders, Philadelphia, pp 478-502

9. Ashikari R, Rosen PP, Urban JA, Senoo T (1976) Breast cancer presenting as an axillary mass. Ann Surg 183:415-417

10. Feigenberg Z, Zer M, Dintsman M (1976) Axillary metastases from an unknown primary source. Israel. J Med Sci 12:1153-1158

11. Vezzoni P, Balestrazzi A, Bignami P, Concolino F, Gennari L, Veronesi U (1979) Axillary lymph node metastases from occult carcinoma of the breast. Tumori 65:87-91

12. Kemeny MM, Rivera DE, Terz JJ, Benfield JR (1986) Occult primary adenocarcinoma with axillary metastases. Am J Surg 152:43-47

13. Bhatia SK, Saclarides TJ, Witt TR, Bonomi PD, Anderson KM, Economou SG (1987) Hormone receptor studies in axillary metastases from occult breast cancers. Cancer 59:1170-1172

14. Campana F, Fourquet A, Ashby MA, Sastre X, Jullien D, Schlienger P et al (1989) Presentation of axillary lymphadenopathy without detectable breast primary: experience at Institut Curie. Radiother Oncol 15:321-325

15. Whillis D, Brown PW, Rodger A (1990) Adenocarcinoma from an unknown primary presenting in women with an axillary mass. Clin Oncol 2:92-198

16. Rosen PP, Kimmel M (1990) Occult breast carcinoma presenting with axillary lymph node metastases. A follow-up study of 48 patients. Hum Pathol 21:518-524

17. Ellerbroek N, Holmes F, Singletary E, Evans H, Oswald M, McNeese M (1990) Treatment of patients with isolated axillary nodal metastases from an occult primary carcinoma consistent with breast origin. Cancer 66:1461-1467

18. Merson M, Andreola S, Galimberi V, Bufalino R, Marchini S, Veronesi U (1992) Breast carcinoma presenting as axillary metastases without evidence of a primary tumour. Cancer 70:504-508

19. Svastics E, Ronay P, Bodo M (1993) Occult breast cancer presenting with axillary metastasis. Eur J Surg Oncol 19(Suppl 1):575-580 
20. Van Ooijen B, Bontenbal M, Henzen-Logmans SC, Koper PCM (1993) Axillary nodal metastases from an occult primary consistent with breast carcinoma. Br J Surg 80(10):1299-1300

21. Kyokane T, Akashi-Tanaka S, Matsui T, Fukutomi T (1995) Clinicopathological characteristics of non-palpable breast cancer presenting as an axillary mass. Breast Cancer 2:105-112

22. Jackson B, Scot-Conner C, Moulder J (1995) Axillary metastasis from occult breast carcinoma: diagnosis and management. Am Surg 61:431-434

23. Foroudi F, Tiver KW (2000) Occult breast carcinoma presenting as axillary metastases. Int J Radiat Oncol Biol Phys 47:143-147

24. Vlastos G, Jean ME, Mirza AN, Mirza NQ, Kuerer HM, Ames FC et al (2001) Feasibility of breast preservation in the treatment of occult primary carcinoma presenting with axillary metastases. Ann Surg Oncol 8:425-431

25. Medina-Franco H, Urist MM (2002) Occult breast carcinoma presenting with axillary lymph node metastases. Rev Invest Clin 54:204-208

26. Shannon C, Walsh G, Sapunar F, Ahern R, Smith I (2002) Occult primary breast carcinoma presenting as axillary lymphadenopathy. Breast 11:414-418

27. Matsuoka K, Ohsumi S, Takashima S, Saeki T, Aogi K, Mandai K (2003) Occult breast carcinoma presenting with axillary lymph node metastases: Follow-up of eleven patients. Breast Cancer 10:330-334

28. Blanchard DK, Farley DR (2004) Retrospective study of women presenting with axillary metastases from occult breast carcinoma. World J Surg 28:535-539

29. Chen C, Orel SG, Harris E, Schnall MD, Czerniecki BJ, Solin LJ (2004) Outcome after treatment of patients with mammographically occult, MRI-detected breast cancer presenting with axillary lymphadenopathy. Clin Breast Cancer 5:72-77

30. Varadarajan R, Edge SB, Yu J, Watroba N, Janarthanan BR (2006) Prognosis of occult breast carcinoma presenting as isolated axillary nodal metastasis. Oncology 71:456-459

31. Iglehart JD, Ferguson BJ, Shingleton WW, Sabiston DC, Silva JS et al (1982) An ultrastructural analysis of breast carcinoma presenting as isolated axillary adenopathy. Ann Surg 196:8-13

32. Vilcoq JE, Calle R, Ferne F, Veith F (1982) Conservative treatment of axillary adenopathy due to probable subclinical breast cancer. Arch Surg 117:1136-1138

33. Pentheroudakis G, Briasoulis GE, Pavlidis N (2007) Cancer of unknown primary site: missing primary or missing biology? Oncologist 12:418-425
34. Haupt HM, Rosen PP, Kinne DW (1985) Breast carcinoma presenting with axillary lymph node metastases. Am J Surg Pathol 9:165-175

35. Ko EY, Han BK, Shin JH, Kang SS (2007) Breast MRI for evaluating patients with metastatic axillary lymph node and initially negative mammography and sonography. Korean J Radiol 8:382-389

36. DeMartinini W, Lehman C, Partridge S (2008) Breast MRI for cancer detection and characterization: a review of evidence-based clinical applications. Acad Radiol 15:408-416

37. Olson JA, Morris EA, Van Zee KJ, Linehan DC, Borgen PI (2000) MR Imaging facilitates breast conservation for occult breast cancer. Ann Surg Oncol 7:411-415

38. Bader AA, Tio J, Petru E, Buchner M, Pfahlberg A, Volkholz H et al (2002) T1 breast cancer: identification of patients at low risk of axillary lymph node metastases. Breast Cancer Res Treat 76(1):11-17

39. Yip CH, Taib NA, Tan GH, Ng KL, Yoong BK, Choo WY (2009) Predictors of axillary lymph node metastases in breast cancer: is there a role for minimal axillary surgery? Worl J Surg 33(1):54-57

40. Buzdar AU (2009) Role of biologic therapy and chemotherapy in hormone-receptor and HER2-positive breast cancer. Ann Oncol 20:993-999

41. Bennett-Britton TM, Purushotham AD (2009) Understanding breast cancer related lymphedema. Surgeon 7:120-124

42. Lacroix M, Toillon TR, Leclercq G (2004) Stable portrait of breast tumours during progression: data from biology, pathology and genetics. Endocr Relat Cancer 11:497-522

43. Besana-Ciani I, Greenhall MJ (2008) The importance of margin status after breast conservative surgery and radiotherapy in nodepositive patients: a follow-up of $10-15$ years. Int Semin Surg Oncol 22:5-13

44. Goldhirsch A, Ingle JN, Gelber RD, Coates AS, Thurlimann B, Senn HJ (2009) Thresholds for therapies: highlights of the Saint Gallen International Expert Consensus on the primary therapy of early breast cancer 2009. Ann Oncol. doi:10.1093/annonc/ mdp322

45. Newman LA, Singletary SE (2007) Overview of adjuvant systemic therapy in early stage breast cancer. Surg Clin North Am 87:499-509

46. Pusztai L (2008) Current status of prognostic profiling in breast cancer. Oncologist 13:350-360 